UCD CENTRE FOR ECONOMIC RESEARCH

WORKING PAPER SERIES

2010

The Economic I mpact of the Little I ce Age

Morgan Kelly and Cormac Ó Gráda, University College Dublin

WP10/14

April 2010

UCD SCHOOL OF ECONOMICS

UNI VERSITY COLLEGE DUBLI N

BELFI ELD DUBLI N 4 


\title{
The Economic Impact of the Little Ice Age.
}

\author{
Morgan Kelly and Cormac Ó Gráda*
}

April 16, 2010

\begin{abstract}
We investigate by how much the Little Ice Age reduced the harvests on which pre-industrial Europeans relied for survival. We find that weather strongly affected crop yields, but can find little evidence that western Europe experienced long swings or structural breaks in climate. Instead, annual summer temperature reconstructions between the fourteenth and twentieth centuries behave as almost independent draws from a distribution with a constant mean but time varying volatility; while winter temperatures behave similarly until the late nineteenth century when they rise markedly, consistent with anthropogenic global warming. Our results suggest that the existing consensus about a Little Ice Age in western Europe stems from a Slutsky effect, where the standard climatological practice of smoothing data prior to analysis induces spurious cyclicality in uncorrelated data.
\end{abstract}

The Little Ice Age is conventionally viewed as a major event of climatic history, with episodes of deep cold causing glaciers to advance, the Thames in London to freeze, and the Norse colonies in Greenland to perish. The consensus among

${ }^{*}$ School of Economics, University College Dublin. This research was undertaken as part of the HI-POD (Historical Patterns of Development and Underdevelopment: Origins and Persistence of the Great Divergence) Project supported by the European Commission's 7th Framework Programme for Research. 
climatologists is that the Northern Hemisphere above the tropics experienced sustained episodes of reduced temperatures between the fifteenth and nineteenth centuries, with particularly marked falls in Europe (Mann 2002, Matthews and Briffa 2005, Mann et al. 2009. We investigate the economic cost of the Little Ice Age: by how much did the worse climate of the period reduce the harvests on which pre-industrial Europeans relied for survival? Although we find that crop yields were strongly affected by weather, we find little evidence of variation in European climate: the distribution of summer temperatures appears unchanged between the fourteenth and twentieth centuries, while winter temperatures remain constant until the late nineteenth century, after which they rise markedly, consistent with global warming. ${ }^{1}$

To analyse how weather affected harvests we use data on cereal yields on over 100 English manors between 1211 and 1450 compiled by Campbell (2007). Manors belonging to religious and other institutions kept detailed annual accounts that give the most accurate information on harvest yields, outside China, before the late nineteenth century. We find that two weather reconstructions have strong explanatory power for annual harvests: Low Countries summer temperatures, and the thickness of annual growth rings of Irish oaks (which correlate with summer precipitation).

A one degree Celsius fall in summer temperature reduced yields of wheat by around 5 per cent, and a one standard deviation rise in summer rainfall reduced yields by around 10 per cent. While yields of the cheaper spring grains on which ordinary people subsisted were less affected by weather, their prices closely followed yields of wheat, the main commercial crop. Epidemic diseases after bad harvests were deadly at all levels of society: a 10 per cent fall in real wages caused by a bad harvest resulted in a 7 per cent rise in mortality among both unfree tenants

\footnotetext{
${ }^{1}$ Strictly speaking, our results give an upper bound for the economic cost of the Little Ice Age, that assumes that people did not shift to cultivating more weather resistant crops during episodes of climatic deterioration. However, because the upper bound for the cost of the Little Ice Age appears to be zero, we did not attempt to refine our estimate.
} 

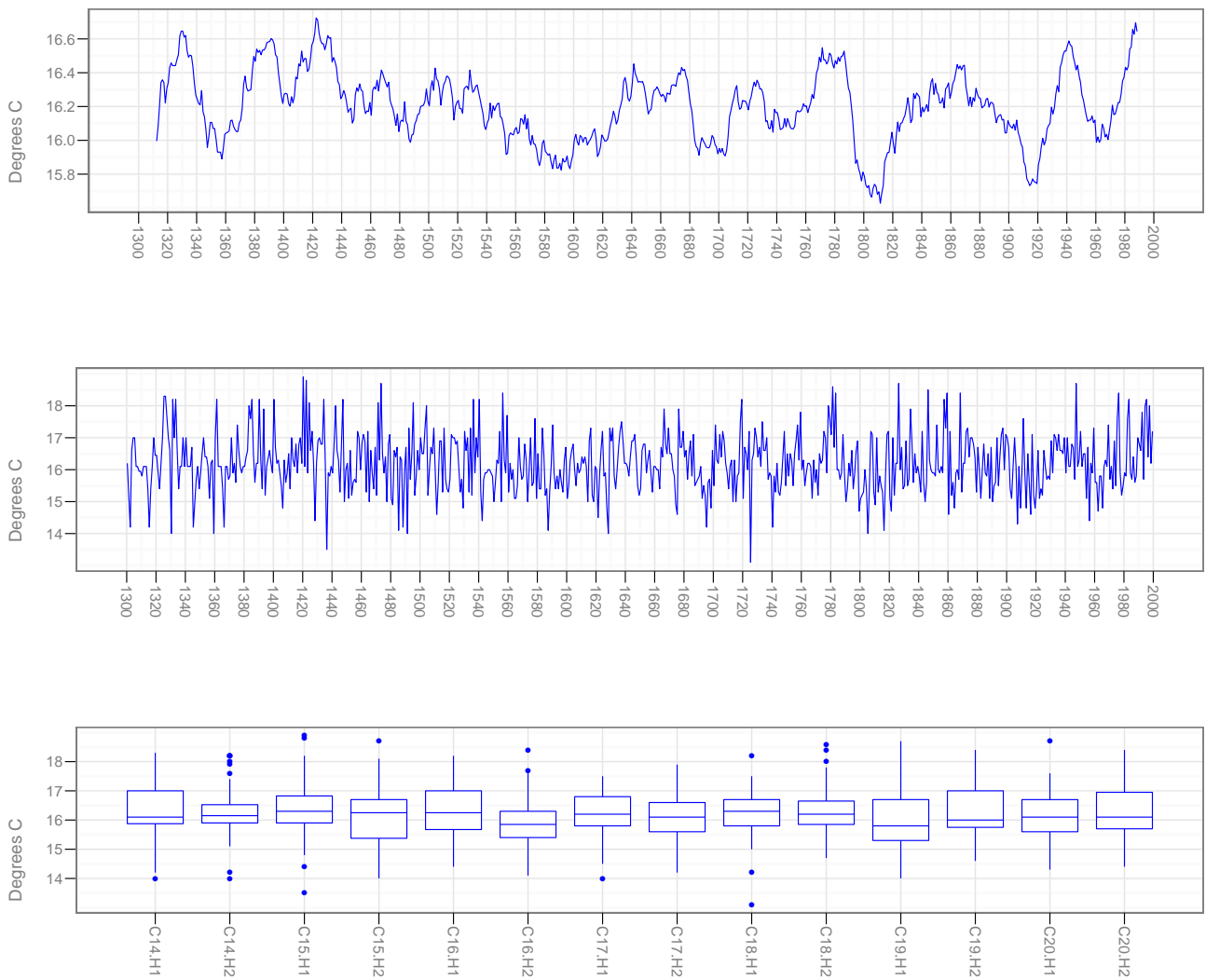

Figure 1: The Slutsky effect in Low Countries summer temperature, AD 13012000. The top panel shows annual temperature smoothed by a 25 year moving average; the middle panel shows the raw series; the bottom panel shows a boxplot of the distribution of temperature by half century.

and the high nobility in the early fourteenth century (Kelly and Ó Gráda, 2010). Bad weather was literally a matter of life and death in pre-industrial Europe.

To see how harvests might have deteriorated during the Little Ice Age we looked at the behaviour of annual weather series between the fourteenth and twentieth centuries. The top panel of Figure 1 shows Low Country summer temperature since 1300 , following the standard climatological practice of smoothing the data, in this case with a 25 year moving average. These smoothed data appear to 
show a cooling trend from the mid-fifteenth to the early nineteenth centuries, with marked cold episodes in the late sixteenth, late seventeenth, and early nineteenth centuries, consistent with the consensus about a Little Ice Age.

However, when we look instead at the unsmoothed data, in the middle panel of Figure 1, the impression is one of randomness without structural breaks, cycles or trends, but with episodes of low and high volatility. Standard statistical tests confirm that this is the case. The bottom panel shows a boxplot of the distribution of temperature by half century, which shows how median summer temperature has fluctuated by a fraction of a degree between 1301 and 2000.

This low autocorrelation in annual levels but strong autocorrelation in variance is not an idiosyncrasy of this one weather series, but is common to most widely used long-run reconstructions of western European weather. In Section 3 we look at the time series behaviour of the Low Countries temperature series, and also historical temperature estimates for Switzerland, France and England; Irish oaks, and rainfall estimates for Switzerland and England.

In nearly all cases we find little dependence in temperature or rainfall between one year and the next, and no evidence of trends. Annual summer temperature in Europe between the fourteenth and twentieth centuries appears as almost independent draws from a distribution with a constant mean but a variance that changes through time. Similarly the distribution of rainfall and winter temperature appears constant until the late nineteenth century, but then changes markedly. Instrumental records of temperature from European cities since the eighteenth century tell a similar story.

In summary, then, annual weather series do not show cycles or structural breaks consistent with a Little Ice Age. Instead their levels show weak autocorrelation while their variances show strong autoregression. This pattern closely resembles the behaviour of a typical financial return series.

That our findings run counter to the existing consensus of a European Little Ice Age reflects our statistical approach. We analyse unsmoothed annual data, whereas the current practice in climatology is to smooth data using a moving 
average or other filter prior to analysis. When data are uncorrelated, as annual European weather series appear to be, smoothing can introduce spurious cycles, a phenomenon first described by Slutsky (1937). ${ }^{2}$ The intuitive reason for the Slutsky effect is straightforward: just as tossing a fair coin leads to long sequences with an excess of heads or tails, so random sequences in general will occasionally throw up some unusually high or low values in close succession. Such outliers, like the bad weather in the 1590s or 1690s in Figure 1, distort smoothing filters and create the misleading appearance of changing climate. Cycles induced by Slutsky effects can occur not only in numerical records, but in physical systems like glaciers which reflect past weather conditions over a number of years.

The rest of the paper is as follows. The traditional view of the Little Ice Age is outlined in Section 1, while the impact of weather on harvests is measured in Section 2. Section 3 looks at possible linear and non-linear dependence in annual reconstructions of weather going back to the middle ages and Section 4 looks at instrumental records in European cities since the eighteenth century. Section 5 concludes.

\section{The Little Ice Age.}

Among Big Theories of human development, few are bigger than the idea that human history before the Industrial Revolution was driven by long cycles in climate. The idea is simple and intuitive: a society's division of labour is constrained by its population and by its surplus of resources over biological subsistence; so the greater resources available in times of mild climate can support greater social complexity.

\footnotetext{
${ }^{2}$ For a lucid derivation of the Slutsky effect, see Sargent $(1979,248-249)$. In the climatology literature Burroughs $(2003,24)$ briefly discusses the Slutsky effect in an early chapter on statistical background and gives a diagram illustrating how applying a moving average to a series of random numbers will give the appearance of cycles, but does not subsequently investigate whether it can be the cause of some perceived climate cycles.
} 
Climate has been extensively invoked to explain the rise and decline of societies ranging from the Maya to the Romans. ${ }^{3}$ It is nearly three decades since de Vries $(1981,624)$ claimed that historians were 'psychologically ready, even eager' to accept climate change as 'a vehicle of long-term historical explanation'. Only more recently, however, economic historians begun to combine historical, economic, and meteorological data in arguing for a link between secular climate change and economic trends in Europe (for instance Steckel 2004, Campbell 2009, Koepke and Baten 2005). Our concern here is with the impact of the Little Ice Age.

Originally coined in 1939 by Matthes to describe the increased extent of glaciers over the last 4,000 years, the term 'Little Ice Age' now usually refers instead to a climatic shift towards colder weather occurring during the second millennium. While climatologists dismiss the idea of the Little Ice Age as a global event, there is a consensus that much of the Northern Hemisphere above the tropics experienced several centuries of reduced mean summer temperatures, although there is some variation over dates with Mann (2002) suggesting the period between the fifteenth and nineteenth centuries, Matthews and Briffa (2005) 1570-1900, and Mann et al. (2009) between 1400 and 1700.

A combination of resonant images invoked by Lamb (1995) has linked the Little Ice Age firmly to Northern Europe. These include the collapse of Greenland's Viking colony and the end of grape-growing in southern England in the fourteenth century; the Dutch winter landscape paintings of Pieter Bruegel (1525-69) and Hendrik Avercamp (1585-1634); the periodic 'ice fairs' on London's Thames, ending in 1814; and, as the Little Ice Age waned, the contraction of Europe's Nordic and Alpine glaciers.

If cooling there was, how much did it matter? The Little Ice Age's impact on agricultural and broader economic trends is controversial. Lamb $(1995,318)$ has drawn attention to the alleged 'parallelism of climatic and cultural curves' as the

\footnotetext{
${ }^{3}$ For a useful survey of theories that invoke climate to explain the collapse of historical societies see Tainter (1988).
} 
Little Ice Age drew to a close. Steckel (2004) has linked the discovery of a downward trend in average adult heights to a cooling trend that 'caused havoc' in northern Europe for several centuries, while Komlos (2003) attributes his finding of a 'very large' increase in French heights in the early eighteenth century to 'a very substantial rise in temperatures'. Other historians who have asserted a strong link between climate change and economic conditions in this era include (Cameron, 1993, 74) and Parker (2001, 5-6). Against such claims, Le Roy Ladurie (1971) and de Vries (1981) have argued that the economic and (by implication) political impact of the Little Ice Age was insignificant.

We now analyse the impact of weather on crop yields, and then estimate how much these yields might have fallen during the Little Ice Age.

\section{Weather and Grain Yields.}

We use data on harvest yields on manors in the south and east of England between 1211 and 1500 compiled by Campbell (2007). While accounts go back to 1211, Campbell (2007) questions their reliability before $1270 .{ }^{4}$ After 1450, manorial production becomes rare and records correspondingly sparse.

\footnotetext{
${ }^{4}$ Some years before 1270 record anomalously high yields, and Postan $(1975,43)$ famously attributed subsequent falls in yields to reduced soil fertility due to over-cropping induced by population pressure. However, if we regress prices on median yields and lagged yields, for the period 1270 to 1450 we find a strong relationship with an $R^{2}$ of 0.5 and elasticities of -0.8 and -0.3 ; but for the period 1211-1269 there is no significant relationship between price and measured yields. If we use the regression coefficients for 1270-1450 to predict price from yields for the earlier period and compare these with actual prices, we find considerable underestimates of price in years with high recorded yields, supporting Campbell's view that high yields in early years are due to accounting errors. Kelly and Ó Gráda (2010) find that records of property transfers on the Winchester manors are fragmentary and unreliable before 1269, again supporting the view that accounting standards were lax before this time.
} 


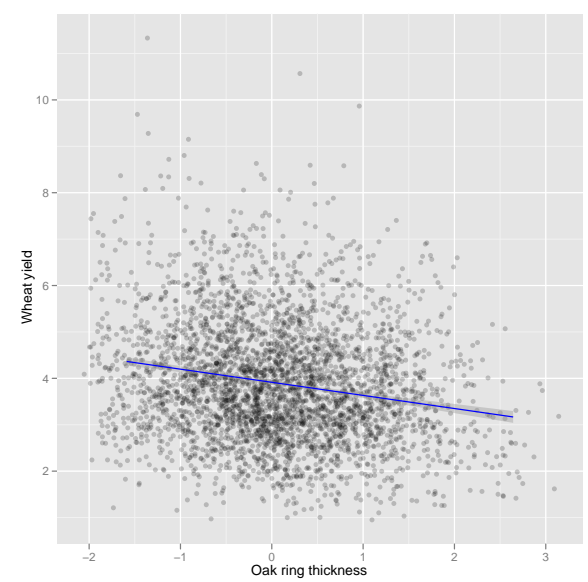

(a) Oak rings.

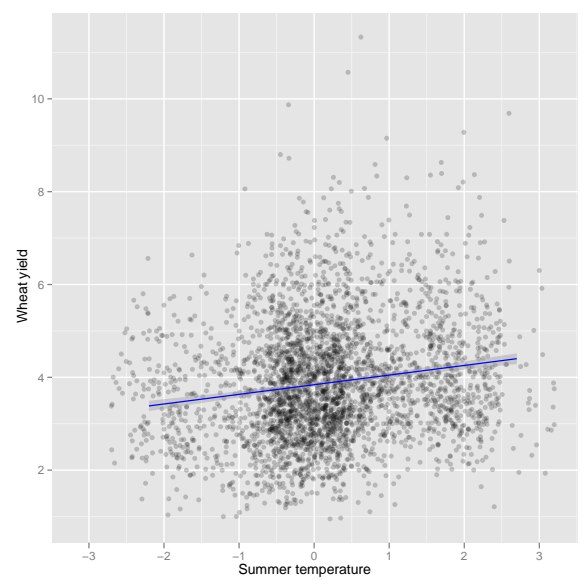

(b) Low Countries Summer temperature.

Figure 2: Impact of weather on wheat yields, 1270-1450

To estimate the impact of weather on yields we run a regression of log yield ratios on weather, allowing intercepts and slopes to vary across manors.

$$
\log y_{i t}=\left(\beta_{0}+\beta_{0 i}\right)+\left(\beta_{1}+\beta_{1 i}\right)\left(s_{t}-\bar{s}\right)+\left(\beta_{2}+\beta_{2 i}\right) r_{t}+\varepsilon_{i t}
$$

where $y_{i t}$ is gross yield per seed on manor $i$ in year $t, s_{t}-\bar{s}$ is the deviation of estimated summer temperature from its mean value, and $r_{t}$ is tree ring thickness expressed in standard deviations from its mean. The intercept and slope have components that vary idiosyncratically across manors $\beta_{j i} \sim N\left(0, \sigma_{\beta_{j}}^{2}\right)$. It follows that the intercept is the log yield ratio in a year with average weather, while the slope coefficients are the average percentage changes in yield due to a one degree change in summer temperature and a one standard deviation change in oak ring thickness. We estimate by restricted maximum likelihood (Pinheiro and Bates, 2000, Ch. 2). Plots of the quantiles of the regression residuals against quantiles of the normal distribution indicate that this semi-log specificiation appears adequate, apart from some very negative residuals presumably due to episodes of crop disease. 


\begin{tabular}{|c|c|c|c|c|c|c|c|c|}
\hline & Intercept & Summer & Rings & Loglik & $\tilde{R}^{2}$ & $\sigma_{\alpha}$ & $\mathrm{N}$ & Manors \\
\hline Wheat & $\begin{array}{c}1.2227^{* *} \\
(0.0197)\end{array}$ & $\begin{array}{c}0.0503^{* *} \\
(0.0049)\end{array}$ & $\begin{array}{c}-0.0565^{* *} \\
(0.004)\end{array}$ & -2389 & 0.2957 & 0.2042 & 8439 & 112 \\
\hline Rye & $\begin{array}{l}1.286^{* *} \\
(0.0285)\end{array}$ & $\begin{array}{l}0.0483^{* *} \\
(0.0169)\end{array}$ & $-0.0321^{* *}$ & -597.2 & 0.1325 & 0.1372 & 1134 & 29 \\
\hline Barley & $\begin{array}{l}1.1805^{* *} \\
(0.0195)\end{array}$ & $\begin{array}{c}0.0035 \\
(0.0052)\end{array}$ & $\begin{array}{c}-0.0087^{* *} \\
(0.0043)\end{array}$ & -2231.4 & 0.2481 & 0.1934 & 7572 & 104 \\
\hline Oats & $\begin{array}{c}0.8742^{* *} \\
(0.0138)\end{array}$ & $\begin{array}{c}0.0201 \\
(0.0051)\end{array}$ & $\begin{array}{c}-0.0042 \\
(0.0042)\end{array}$ & -2648.2 & 0.1519 & 0.1417 & 8290 & 116 \\
\hline
\end{tabular}

Mixed effects regression of log cereal yield ratio on on estimated summer temperatures (deviation from mean value of 15.3 Celsius) and oak ring thickness. Intercept varies across manors: $\sigma_{\alpha}$ is its standard deviation. $\mathrm{N}$ is number of observations and Manors is the number of manors . $\tilde{R}^{2}$ is the pseudo- $R^{2}$ for each regression. Standard errors in parentheses. * denotes significance at 5 percent, ** at 1 percent.

Table 1: Cereal yields and weather, 1211-1500

While intercepts, which denote average yield, vary widely across manors, there is little evidence for variation of slopes: comparing log-likelihood of regressions with fixed and variable slopes produced an improvement in fit that was significant at conventional levels only for the case of summer temperature on wheat, and even then the improvement in fit was small. For the results reported in Table 1 , only the intercept varies across manors.

The small number of observations for some manors led to occasional difficulties with convergence, so we include only manors with at least 10 observations.

Given the mild climate of the southern England, our expectation was that slight variations in temperature and rainfall each year would hardly affect yields outside well known periods of severe weather such as the heavy rains of 1315-16. In fact, wheat yield turns out to be strongly affected by weather: a one degree rise in summer temperature (equivalent to a change of 1.5 standard deviations) increases average yield by 3.5 per cent, while a one standard deviation increase in oak ring thickness is associated with a fall of 5.4 per cent in average output. As mentioned, the effect of summer temperature varies considerably across manors: estimated slopes range from zero to 0.12 with the strongest effects on manors with the highest yields: the correlation between estimated slopes and intercepts is 0.6. Winter temperature had no apparent explanatory power for yields. Including squared tem- 


\begin{tabular}{lcccc}
\hline & Wheat & Rye & Barley & Oats \\
\hline Wheat & & 0.477 & 0.338 & 0.237 \\
Rye & 0.884 & & 0.370 & 0.305 \\
Barley & 0.852 & 0.831 & & 0.599 \\
Oats & 0.811 & 0.761 & 0.876 & \\
\hline
\end{tabular}

Table 2: Correlation between annual yields (above diagonal), and nominal prices (below diagonal) of cereals, 1270-1450.

perature and oak rings, to allow for possible non-linear effects of weather, did not produce large or significant effects.

One thing we know for certain about our weather estimates is that they are measured with error, and their coefficient estimates suffer in consequence from attenuation bias. Using the textbook errors in variable formula, based on the known relationship of the variables between 1766 and 1900, a regression using Dutch summer temperature and oak ring thickness as proxies for English summer temperature and rainfall respectively will produce coefficients that are 70 per cent and 48 per cent respectively of their true values, and to the extent that medieval temperature estimates are less accurate than these later observations, the underestimate for temperature will be correspondingly larger.

Other crops were less sensitive to weather, in the order that we would expect. Rye has similar coefficients to wheat, while the spring grains barley and oats show no measurable effect of rainfall, although oats show a slightly positive effect of summer temperature.

We see that, in terms of weather risk, spring grains offered the best insurance to subsistence farmers, and have the added advantages of growing on poorer soil than wheat, and producing more calories per acre. While we know from medieval accounts that the staple food of servants, outside harvest time, was dredge, a mixture of barley and oats, Kelly and Ó Gráda (2010) show that a better predictor of mortality at all levels of society in the century before the Black Death was wheat yields. This reflects the fact that most families had too little land to support 
themselves, and worked for wages whose purchasing power reflected wheat yields which determined the prices of other grains. As Table 2 shows, yields of other cereals are poorly correlated with wheat, but their prices are strongly correlated.

\section{Climate Since the Middle Ages.}

To look at how weather deteriorated during the Little Ice Age we analyse several widely used annual climate reconstructions up to 2000 for Western Europe, summarized in Table 3: Low Countries Summer and Winter temperature from 1301; ${ }^{5}$ French summer temperature from 1370; Swiss summer and winter temperature and precipitation from 1525; English summer and winter temperature from 1660, and precipitation from 1766 . We also consider two other series that reflect weather conditions: Irish oaks from 1301 and English wheat yields from 1270.

We start by looking at the stability of each series: can we find structural breaks corresponding to different phases of climate. To do this we apply a Bai and Perron (1998) procedure to detect breakpoints in a regression of annual weather on a constant (including autoregressive terms and a trend did not alter our results materially). We break each series in Table 3 according to the detected break dates. It can be seen that the winter temperature series show a consistent pattern, with a break occurring in every case around the end of the nineteenth century, with temperature rising by $0.6-0.8 \mathrm{C}$. This common trend appears consistent with global warming. Similarly, winters appear to become wetter at this time, in both England and Switzerland.

Summer temperatures by contrast show no break in the Low Countries, Swiss or English data, while the French data break in 1728 at the time when the modern mercury thermometer is introduced. Swiss summers become noticeably drier after

\footnotetext{
${ }^{5}$ Although these series start in $\mathrm{AD} 800$, there are increasing numbers of missing observations as we go back past 1301 and the authors are less confident of their accuracy, putting them in wider bands that they denote by Roman rather than Arabic numerals. In running times series tests, missing observations during the 14th and early 15 th centuries ( 30 for winter, 11 for summer) were set at the median value of the entire series. Running tests from the mid-15th century did not change the reported results materially.
} 


\begin{tabular}{lrrrrrrr}
\hline & Start & Mean & SD & K-W & $\rho$ & Trend & $R^{2}$ \\
\hline & \multicolumn{7}{c}{ Temperature } \\
Netherlands summer & 1301 & 16.206 & 0.908 & 0.358 & $0.102^{* *}$ & 0.000 & 0.011 \\
Netherlands winter & 1301 & 1.685 & 1.644 & 0.305 & -0.056 & 0.000 & 0.003 \\
& 1861 & 2.478 & 1.714 & 0.214 & 0.135 & 0.005 & 0.036 \\
France summer & 1370 & 0.044 & 1.03 & 0.008 & $0.178^{* *}$ & 0.000 & 0.032 \\
& 1728 & -0.268 & 0.76 & 0.035 & -0.083 & $0.002^{* *}$ & 0.041 \\
Switzerland summer & 1525 & -0.043 & 0.995 & 0.040 & 0.068 & 0.000 & 0.007 \\
Switzerland winter & 1525 & -0.426 & 1.146 & 0.077 & $-0.139^{* *}$ & $-0.001^{*}$ & 0.028 \\
& 1909 & 0.126 & 1.217 & 0.754 & 0.086 & -0.001 & 0.008 \\
England summer & 1660 & 15.284 & 0.807 & 0.012 & 0.099 & 0.001 & 0.015 \\
England winter & 1660 & 3.468 & 1.348 & 0.013 & -0.056 & 0.002 & 0.016 \\
& 1895 & 4.348 & 1.287 & 0.555 & 0.109 & 0.007 & 0.048 \\
Switzerland summer & 1525 & 0.216 & 0.972 & 0.035 & $0.120^{*}$ & -0.000 & 0.022 \\
& 1812 & -0.072 & 0.907 & 0.028 & -0.016 & 0.002 & 0.009 \\
Switzerland winter & 1525 & -0.243 & 0.859 & 0.251 & -0.025 & -0.001 & 0.008 \\
& 1899 & 0.246 & 0.997 & 0.365 & 0.037 & 0.005 & 0.019 \\
England summer & 1766 & 451.132 & 89.833 & 0.152 & 0.087 & -0.167 & 0.012 \\
& 1883 & 414.459 & 76.34 & 0.368 & -0.025 & 0.125 & 0.004 \\
England winter & 1766 & 450.259 & 81.516 & 0.596 & 0.048 & 0.024 & 0.002 \\
& 1864 & 505.361 & 90.588 & 0.349 & -0.072 & 0.256 & 0.016 \\
Irish oaks & 1301 & 0.000 & 1.006 & 0.879 & $0.332^{* *}$ & 0.000 & 0.111 \\
English wheat & 1270 & 3.586 & 0.558 & 0.635 & 0.117 & 0.001 & 0.010 \\
\hline
\end{tabular}

$\mathrm{K}-\mathrm{W}$ is the $p$-value of the Kruskal-Wallis rank sum test where data are grouped by half century. Followed by autoregressive coefficient $\rho$ and trend coefficients, and squared correlation $R^{2}$ for AR(1) regression with time trend. ** denotes a coefficient significant at 1 per cent, estimated with Andrews HAC standard errors. Swiss data end in 1989, Irish oaks in 1993, and English wheat in 1450.

Table 3: Summary statistics and tests of autoregression and trend for annual weather indicators until 2000.

the 1810s, and English ones after the 1880s. Among other series, the thickness of Irish oak growth rings and English medieval yields remain constant.

Next we ask if different half centuries had different temperatures using a Kruskall-Wallis procedure to test if different half centuries have higher or lower ranked temperature. Because our data are close to normal, the results in each case are the same as the $p$-value of a regression of annual temperature on dummy 
variables or factors for each half century. For the Low Countries summer series, the outcome is far from significance: there appears to be no difference in summer temperatures between 1300 and 2000. For England, Switzerland and France after 1728 , the test is significant however at 1 per cent, 2 per cent and 3 per cent respectively.

Carrying out pairwise comparisons of means by half century using Tukey's honest significant difference calculation of $p$-values, we find that the English result is driven by the earliest, and possibly less accurate, observations in the late seventeenth century, which are about $0.5 \mathrm{C}$ below eighteenth century values: there are no significant differences in summer temperatures between the early eighteenth and late twentieth centuries. For Switzerland, significance occurs because of the difference between the early eighteenth and nineteenth centuries; while pairwise comparisons find no significant different between any pair of half centuries for France after 1700. Testing for equality of variance across half-centuries, using a Fligner-Killeen test, led to strong rejection in every case: weather shows strong autoregressive conditional heteroskedasticity as we will see below.

The last three columns of Table 3 give the results of a first order autoregression with trend for each weather series. Partial autocorrelation plots of residuals indicate that an AR1 process is an adequate specification. ${ }^{6}$ It can be seen that the only series with a statistically significant trend is French temperature after 1728, although the effect is small: 0.2 degrees per century. For every series-except Irish oaks which are large, slow growing organisms-the $R^{2}$ of the AR1 process is below 0.05 and in most cases below 0.02 . Only a few series, apart from oaks, show significant autoregression. The significance of the Dutch series is caused by reconstructions from the fourteenth century, and disappears from the fifteenth century onwards. Similarly, the negative autocorrelation in the Swiss winter temperature series disappears when observations before 1700 are excluded. The only temperature series that shows robust autocorrelation is French summer temperature before 1728, although this possibly reflects autocorrelation in the start dates

\footnotetext{
${ }^{6}$ The exception is Irish oaks, which show a weak but significant autocorrelation at 6 years.
} 
of wine harvests rather than underlying temperatures. Among precipitation series, only Swiss summers before 1812 show significant autoregression, but again this disappears if the first hundred years of data are omitted. While weather data show weak dependence, they are not entirely random: a tests of runs above or below the mean of each series is significant in every case.

It is interesting that while annual Swiss winter temperature and precipitation are close to random until the late nineteenth century, Swiss glaciers fluctuate notably, expanding from the mid-fifteenth century until 1650, contracting until 1750 and then expanding again until 1850 (Matthews and Briffa, 2005, 18-19). Glaciers can be seen as a physical example of a Slutsky effect: their extent represents a moving average process of temperature and precipitation over preceding years, and can show considerable variation through time even though the annual weather processes that drive them are random.

\subsection{Non-linear dependence.}

While the results in Table 3 suggest that there is weak linear dependence between annual temperature and precipitation, this does not rule out the possibility that weather series show non-linear dependence. Table 4 reports tests for nonlinear dependence in the same weather series. Breaking the series at the structural breakpoints in Table 3 did not alter the results materially, so we present statistics for the complete series here.

The first two columns report the estimated Hurst exponent (calculated using detrended fluctuation analysis) and its standard error. A Hurst exponent measures how fast the range of observations grows through time. Values of 0.5 indicates random observations, with higher values indicating trending, and low values mean reversion. It can be seen that the English and Swiss winter temperature series are close to 0.5 , with the summer temperature series showing some small degree of trending, with values towards 0.6 .

The next column reports the Brock et al. (1996) test of independence for an embedding dimension of 3 and epsilon of 2 standard deviations. Again, only 


\begin{tabular}{llccccc}
\hline & $H$ & $\sigma_{H}$ & BDS & TLG & GARCH & $\sigma_{G}$ \\
\hline \multicolumn{7}{c}{ Temperature } \\
Netherlands summer & 0.523 & 0.013 & 0.286 & 0.096 & 0.642 & 0.003 \\
Netherlands winter & 0.562 & 0.015 & 0.855 & 0.609 & 0.785 & 0.011 \\
France summer & 0.594 & 0.019 & 0.000 & 0.221 & 0.174 & 0.003 \\
Switzeland summer & 0.624 & 0.022 & 0.227 & 0.434 & 0.888 & 0.003 \\
Switzerland winter & 0.51 & 0.012 & 0.046 & 0.697 & 0.959 & 0.007 \\
England summer & 0.579 & 0.016 & 0.523 & 0.883 & 0.819 & 0.004 \\
England winter & 0.472 & 0.023 & 0.509 & 0.503 & 0.804 & 0.003 \\
& 0.637 & 0.022 & 0.256 & 0.071 & 0.934 & 0.192 \\
Switzerland summer & 0.637 & 0.003 & 0.003 \\
Switzerland winter & 0.57 & 0.013 & 0.777 & 0.003 & 0.803 & 0.013 \\
England summer & 0.48 & 0.03 & 0.466 & 0.446 & 0.766 & 0.006 \\
England winter & 0.634 & 0.03 & 0.24 & 0.766 & 0.865 & 0.002 \\
& 0.545 & 0.027 & 0.269 & 0.274 & 0.799 & 0.000 \\
English wheat & 0.393 & 0.037 & 0.000 & 0.551 & 0.999 & \\
Irish oaks &
\end{tabular}

$H$ and $\sigma_{H}$ are the estimated Hurst exponent and its standard error; BDS is the $p$-value of a BDS test with embedding dimension of 3 with an epsilon value of 2 standard deviations; TLG is the p-value of a Terasvirta-Lin-Granger test for non-linearity in means; GARCH is the coefficient on lagged variance in an $\operatorname{AR} 1$ model with $\operatorname{GARCH}(1,1)$ errors, and $\sigma_{G}$ is its standard error.

Table 4: Tests for non-linear dependence in annual weather series.

French summer and Irish oaks show significant deviations from independence. Next the Teraesvirta, Lin and Granger (1993) test for non-linearity in means is reported and, in this case, only the Swiss winter rain series shows significant departures from linearity.

While the levels of most temperature and rainfall series show little autoregression, their variances do. Specifically we assumed that each series followed an AR1 process: $y_{t}=\beta_{0}+\beta_{1} y_{t-1}+\varepsilon_{t}$ where the variance $\sigma_{t}^{2}$ of $\varepsilon_{t}$ follows a $\operatorname{GARCH}(1,1)$ process $\sigma_{t}^{2}=\alpha_{0}+\alpha_{1} \varepsilon_{t-1}^{2}+\alpha_{2} \sigma_{t-1}^{2}$ estimated assuming a skewed generalized error distribution. In all cases we found that the state coefficient $\alpha_{1}$ was close to zero, and the final two columns of Table 4 report the coefficient and standard error of the variance coefficient $\alpha_{2}$. It can be seen that, with the exception again 
of the unusual French summer estimates, all series shows strong autoregressive heteroskedasticity.

Applying a Markov switching model to the data in each case indicated fairly rapid transitions between two regimes with equal means but high and low variances; again consistent with GARCH. Like financial return series, annual weather shows weak dependence in levels, but strong autoregression in variance.

\section{Weather in Cities}

In the previous Section we saw that a variety of long-run weather constructions for Europe indicate that annual weather shows little dependence from year to year, and that summer temperatures during the twentieth century differ little from those in earlier centuries during the supposed Little Ice Age.

A natural objection to these findings is that these long run weather reconstructions rely at times on strong assumptions, that vitiate any conclusions drawn from them. It is therefore worthwhile to see if later, more systematic weather series behave similarly. We therefore examine summer and winter temperatures for European cities in the CDIAC "Updated Global Grid Point Surface Air Temperature Anomaly Data Set: 1851-1990," selecting all cities where continuous records go back to 1799 or earlier.

Table 5 looks at temporal dependence in winter temperature. Again, series are broken where a Bai-Perron procedure indicates structural breaks in levels. Just like the long-run winter reconstructions in Table 3, the winter temperature series tend to break in the late nineteenth or early twentieth centuries, with a higher temperature after the break, consistent with global warming. Again, a first order autoregression with trend finds little evidence of a significant trend or autoregression in the data.

Table 6 repeats the exercise for summer temperature. In this case however, the data appear a considerably noisier with breaks occurring in one city but not in nearby neighbours, and falls occurring as well as rises. It would appear that most 


\begin{tabular}{|c|c|c|c|c|c|c|c|}
\hline & Start & Mean & SD & $\mathrm{K}-\mathrm{W}$ & $\rho$ & Trend & $R^{2}$ \\
\hline Berlin & 1757 & 0.198 & 2.11 & 0.025 & 0.067 & 0.002 & 0.011 \\
\hline \multirow[t]{2}{*}{ Budapest } & 1781 & -0.28 & 1.824 & 0.291 & -0.077 & -0.007 & 0.021 \\
\hline & 1897 & 0.696 & 1.708 & 0.253 & 0.088 & 0.005 & 0.013 \\
\hline \multirow[t]{2}{*}{ Copenhagen } & 1799 & -0.317 & 1.733 & 0.12 & 0.047 & 0.005 & 0.01 \\
\hline & 1898 & 0.847 & 1.585 & 0.684 & 0.089 & 0.004 & 0.012 \\
\hline \multirow[t]{2}{*}{ De Bilt } & 1707 & 1.852 & 1.837 & 0.397 & -0.119 & -0.002 & 0.016 \\
\hline & 1859 & 2.607 & 1.658 & 0.604 & 0.1 & -0.001 & 0.01 \\
\hline \multirow[t]{2}{*}{ Edinburgh } & 1765 & 2.907 & 1.212 & 0.49 & -0.168 & 0.003 & 0.03 \\
\hline & 1832 & 3.749 & 1.093 & 0.246 & -0.073 & 0.004 & 0.025 \\
\hline \multirow[t]{2}{*}{ Geneva } & 1754 & 0.278 & 1.447 & 0.982 & -0.058 & 0.002 & 0.007 \\
\hline & 1910 & 1.366 & 1.33 & 0.362 & 0.082 & 0.005 & 0.012 \\
\hline \multirow[t]{2}{*}{ Milan } & 1764 & 2.198 & 1.363 & 0.454 & -0.028 & -0.004 & 0.013 \\
\hline & 1896 & 2.82 & 1.165 & 0.02 & 0.069 & $-0.014^{* *}$ & 0.106 \\
\hline Munich & 1782 & -1.193 & 1.882 & 0.784 & 0.025 & 0.000 & 0.001 \\
\hline \multirow[t]{2}{*}{ Paris } & 1758 & 3.142 & 1.565 & 0.467 & -0.122 & -0.003 & 0.022 \\
\hline & 1910 & 3.897 & 1.522 & 0.501 & 0.08 & -0.004 & 0.01 \\
\hline Petersburg & 1753 & -7.128 & 2.669 & 0.489 & -0.04 & $0.006^{*}$ & 0.019 \\
\hline Prague & 1775 & -2.219 & 2.165 & 0.074 & 0.086 & 0.005 & 0.028 \\
\hline \multirow[t]{2}{*}{ Stockholm } & 1757 & -3.413 & 2.19 & 0.862 & -0.023 & 0.007 & 0.0139 \\
\hline & 1882 & -2.186 & 1.994 & 0.431 & 0.088 & 0.000 & 0.008 \\
\hline \multirow[t]{3}{*}{ Trondheim } & 1762 & -2.915 & 1.8 & 0.595 & $-0.18^{* *}$ & 0.006 & 0.047 \\
\hline & 1904 & -1.274 & 1.61 & 0.236 & 0.222 & 0.008 & 0.052 \\
\hline & 1940 & -2.698 & 2.001 & 0.443 & 0.165 & -0.008 & 0.03 \\
\hline \multirow[t]{2}{*}{ Vienna } & 1776 & -0.643 & 1.913 & 0.581 & -0.052 & -0.007 & 0.016 \\
\hline & 1897 & 0.21 & 1.784 & 0.55 & 0.158 & 0.001 & 0.025 \\
\hline \multirow[t]{2}{*}{ Warsaw } & 1780 & -3.608 & 2.433 & 0.409 & 0.042 & 0.008 & 0.011 \\
\hline & 1873 & -2.219 & 2.067 & 0.202 & 0.083 & $0.002^{* *}$ & 0.008 \\
\hline Wroclaw & 1793 & -1.117 & 2.316 & 0.018 & 0.128 & 0.006 & 0.045 \\
\hline
\end{tabular}

$\mathrm{K}-\mathrm{W}$ is the $p$-value of the Kruskal-Wallis rank sum test where data are grouped by half century. Followed by autoregressive coefficient $\rho$ and trend coefficients, and squared correlation $R^{2}$ for $\mathrm{AR}(1)$ regression with time trend. ** denotes a coefficient significant at 1 per cent, * at 5 per cent, estimated with Andrews HAC standard errors.

Table 5: Summary statistics and tests of temporal dependence for annual winter temperature until 1980.

structural breaks in these data reflect changes in recording methodology. Again, however, the data for the most part do not exhibit significant autoregression or trends. 


\begin{tabular}{|c|c|c|c|c|c|c|c|}
\hline & Start & Mean & SD & K-W & $\rho$ & Trend & $R^{2}$ \\
\hline \multirow[t]{3}{*}{ Berlin } & 1756 & 17.798 & 1.045 & 0.225 & 0.178 & -0.019 & 0.116 \\
\hline & 1799 & 17.026 & 0.918 & 0.004 & $0.199^{*}$ & $0.008^{* *}$ & 0.128 \\
\hline & 1894 & 16.939 & 0.9 & 0.002 & 0.135 & 0.007 & 0.07 \\
\hline \multirow[t]{2}{*}{ Budapest } & 1780 & 20.888 & 0.932 & 0.235 & 0.016 & -0.025 & 0.068 \\
\hline & 1812 & 19.994 & 0.859 & 0.000 & $0.185^{*}$ & -0.001 & 0.038 \\
\hline \multirow[t]{3}{*}{ Copenhagen } & 1798 & 15.77 & 1.091 & 0.355 & 0.05 & -0.002 & 0.004 \\
\hline & 1836 & 15.253 & 0.924 & 0.005 & 0.074 & $0.008^{*}$ & 0.081 \\
\hline & 1942 & 16.023 & 0.816 & 0.15 & 0.053 & -0.008 & 0.016 \\
\hline \multirow[t]{3}{*}{ De Bilt } & 1706 & 15.681 & 0.826 & 0.095 & $0.262^{* *}$ & * $\quad 0.001$ & 0.068 \\
\hline & 1849 & 17.245 & 0.828 & 0.004 & 0.046 & -0.005 & 0.026 \\
\hline & 1940 & 16.095 & 1.231 & 0.000 & $0.278^{* *}$ & $-0.039^{* *}$ & 0.323 \\
\hline Edinburgh & 1764 & 13.579 & 0.713 & 0.005 & 0.129 & -0.001 & 0.019 \\
\hline \multirow[t]{3}{*}{ Geneva } & 1753 & 16.874 & 0.641 & 0.055 & 0.101 & 0.005 & 0.028 \\
\hline & 1808 & 16.369 & 0.881 & 0.065 & 0.079 & 0.004 & 0.029 \\
\hline & 1928 & 17.058 & 0.816 & 0.057 & -0.101 & $-0.015^{*}$ & 0.072 \\
\hline \multirow[t]{4}{*}{ Milan } & 1763 & 21.943 & 0.871 & 0.074 & $0.227^{*}$ & -0.007 & 0.091 \\
\hline & 1831 & 20.897 & 0.775 & 0.092 & -0.26 & $0.042^{* *}$ & 0.234 \\
\hline & 1863 & 22.318 & 0.812 & 0.002 & $0.307^{* *}$ & * $\quad 0.008^{* *}$ & 0.197 \\
\hline & 1949 & 21.081 & 1.031 & 0.012 & 0.245 & -0.027 & 0.203 \\
\hline \multirow[t]{2}{*}{ Munich } & 1781 & 16.224 & 0.837 & 0.754 & 0.138 & 0.000 & 0.016 \\
\hline & 1812 & 15.707 & 0.832 & 0.004 & 0.069 & 0.002 & 0.015 \\
\hline \multirow[t]{2}{*}{ Paris } & 1757 & 18.634 & 1.186 & 0.000 & 0.176 & $-0.071^{* *}$ & 0.543 \\
\hline & 1790 & 17.121 & 0.925 & 0.000 & 0.106 & -0.001 & 0.016 \\
\hline \multirow[t]{2}{*}{ Petersburg } & 1752 & 16.14 & 1.102 & 0.078 & -0.011 & $-0.007^{* *}$ & 0.052 \\
\hline & 1881 & 14.937 & 1.026 & 0.002 & 0.026 & 0.006 & 0.034 \\
\hline \multirow[t]{2}{*}{ Prague } & 1774 & 16.78 & 1.067 & 0.3 & 0.207 & 0.000 & 0.043 \\
\hline & 1837 & 16.004 & 0.882 & 0.000 & 0.159 & 0.002 & 0.045 \\
\hline \multirow[t]{3}{*}{ Stockholm } & 1756 & 15.098 & 1.111 & 0.194 & 0.112 & -0.003 & 0.02 \\
\hline & 1860 & 14.331 & 0.922 & 0.273 & -0.141 & 0.001 & 0.02 \\
\hline & 1932 & 15.378 & 0.87 & 0.139 & 0.083 & -0.01 & 0.036 \\
\hline \multirow[t]{2}{*}{ Trondheim } & 1761 & 12.721 & 1.127 & 0.69 & 0.132 & -0.001 & 0.018 \\
\hline & 1862 & 12.069 & 0.984 & 0.057 & 0.042 & -0.001 & 0.003 \\
\hline \multirow[t]{2}{*}{ Vienna } & 1775 & 18.551 & 1.046 & 0.765 & 0.241 & 0.007 & 0.064 \\
\hline & 1812 & 17.696 & 0.808 & 0.001 & 0.147 & 0.000 & 0.022 \\
\hline Warsaw & 1779 & 16.771 & 0.951 & 0.003 & 0.12 & -0.001 & 0.02 \\
\hline \multirow[t]{2}{*}{ Wroclaw } & 1792 & 16.259 & 1.199 & 0.157 & 0.213 & -0.007 & 0.053 \\
\hline & 1834 & 16.763 & 0.787 & 0.001 & 0.029 & -0.003 & 0.028 \\
\hline
\end{tabular}

Table 6: Summary statistics and tests of temporal dependence for annual summer temperature until 1980.

\section{Conclusions.}

Our intention was to estimate the extent and timing of climate changes during the Little Ice Age, and to gauge their impact on food production based on known crop yields from medieval times. Instead we discovered that standard weather reconstructions, so long as they are not smoothed before analysis, show little autocorrelation. Instead of a Little Ice Age, annual summer weather conditions in western 
Europe between 1300 and 2000 are weakly dependent draws from a distribution with a fixed mean but autocorrelated variance; while winter weather behaves similarly until around 1900, but then warms notably.

Climate therefore appears to have played little role in reducing the harvests on which pre-industrial Europeans relied for survival. Our finding is a reminder that some of the changes claimed by Lamb (1995) to be consequences of the Little Ice Age have other possible causes. The freezing of the Thames-which for most people is the most salient fact about the Little Ice Age-was due to Old London Bridge which effectively acted as a dam, creating a large pool of still water which froze 12 times between 1660 and 1815. Tidal stretches of the river have not frozen since the bridge was replaced in 1831, even during 1963 which is the third coldest winter (after 1684 and 1740) in the Central England temperature series that starts in 1660 .

Among Dutch artists, Avercamp made a living from his formulaic winter scenes, but such snowscapes rarely feature in the work of his better known contemporaries, such as Albert Cuyp, Jan van Goyen, or Salomon van Ruisdael. It bears noting that Breugel's iconic 'Hunters in the Snow' was one of a series of six paintings describing different seasons of the year and that none of the others hints at a Little Ice Age.

For Greenland's Vikings, competition for resources with the indigenous Inuit, the decline of Norwegian trade in the face of an increasingly powerful German Hanseatic League, the greater availability of African ivory as a cheaper substitute for walrus ivory, overgrazing, plague, and marauding pirates probably all played some role in its demise (Brown, 2000); and even if weather did worsen, the more fundamental question remains of why Greenland society failed to adapt (McGovern, 1981). The disappearance of England's few vineyards is associated with increasing wine imports after Bordeaux passed to the English crown in 1152, suggesting that comparative advantage may have played a larger role than climate.

Similarly, the decline of wheat and rye cultivation in Norway from the thirteenth century may owe more to lower German cereal prices than temperature 
change (Miskimin, 1975, 59). With worsening climate we would expect wheat yields to fall relative to barley oats (see Table 1) whereas Apostolides et al. (2008, Tables 1A, 1B) find that between the early fifteenth and late seventeenth century, wheat yields show no trend relative to oats, and rise steadily relative to barley.

Finally, demography supports our reservations about a European Little Ice Age. We would expect northern Europe to have shown weak population growth as the Little Ice Age forced back the margin of cultivation. In fact, while the population of Europe in 1820 was roughly 2.4 times what it had been in 1500, in Norway the population was about 3.2 times as large, in Switzerland 3.5 times, in Finland 3.9 times, and in Sweden 4.7 times as large as in 1500 (Maddison, 2009).

\section{Appendix: Data Sources and Estimation}

- Monthly mean Central England temperature from 1659 are from http://hadobs.metoffice.com/hadcet/cetml1659on.dat, and the monthly England and Wales precipitation series from 1766 are from http://hadobs.metoffice.com/hadukp/data/monthly/HadEWP_monthly_qc.txt.

- The Low Countries temperature series of van Engelen, Buisman and IJnsen (2001) are available at www.knmi.nl/kd/metadata/nederland_wi_zo.html.

- Spring-Summer temperatures in Burgundy, expressed as the deviation from the 1960-1989 average from Chuine et al. (2004) are available at http://www.ncdc.noaa.gov/paleo/pubs/chuine2004/chuine2004.html

- Swiss summer and winter temperature and precipitation from Pfister (1992) are available at ftp://ftp.ncdc.noaa.gov/pub/data/paleo/historical/switzerland/clinddef.txt

- Irish oak ring widths, measured as standard deviations from their mean, are annual deviations from a 30 year moving average. Provided by Professor Michael Baillie, Palaeoecology Centre, The Queen's University of Belfast. 
- European cities summer and winter temperatures are averages of June to August, and December to January temperatures from the jonesnh.dat file in "An Updated Global Grid Point Surface Air Temperature Anomaly Data Set: 1851-1990" available at http://cdiac.ornl.gov/ftp/ndp020/.

- Crop yield data are from Campbell (2007): http://www.cropyields.ac.uk.

- Price data are taken from Robert Allen's database of Prices and Wages in London and Southern England, 1259-1914 (http://www.nuff.ox.ac.uk/users/allen/studer/london.xls).

- Estimation was carried out in $R$. Panel regressions were estimated using the lme4 module, BDS and Teraesvirta tests from tseries module, GARCH from fGarch module, and the Hurst exponent from the fARMA module.

\section{References}

Apostolides, Alexander, Stephen Broadberry, Bruce Campbell, Mark Overton and Bas van Leeuwen. 2008. English Gross Domestic Product, 1300-1700: Some Preliminary Estimates. Working paper University of Warwick. 20

Bai, Jushan and Pierre Perron. 1998. "Estimating and Testing Linear Models With Multiple Structural Changes.” Econometrica 66:47-78. 11

Brock, W.A., W.D. Dechert, B. LeBaron and J.A. Scheinkman. 1996. "A Test for Independence Based on the Correlation Dimension." Econometric Reviews 15:197-235. 14

Brown, Dale M. 2000. "The Fate of Greenland's Vikings.” Archaeology . Available online: http://www.archaeology.org/online/features/greenland. 19

Burroughs, William James. 2003. Weather Cycles: Real or Imaginary? Second ed. Cambridge: Cambridge University Press. 5 
Cameron, Rondo E. 1993. A Concise Economic History of the World. Oxford: Oxford University Press. 7

Campbell, Bruce M. S. 2007. Three Centuries of English Crops Yields, 12111491. WWW Document. URL http://www.cropyields.ac.uk. 2, 7, 21

Campbell, Bruce M.S. 2009. "Nature as Historical Protagonist." Economic History Review . 6

Chuine, Isabelle, Isabelle Yiou, Nicolas Viovy, Bernard Seguin, Valerie Daux and Emmanuel Le Roy Ladurie. 2004. "Grape ripening as a past climate indicator." Nature 432(289-290). 20

de Vries, Jan. 1981. Measuring the Impact of Climate on History: The Search for Appropriate Methodologies. In Climate and History, ed. Robert I. Rotberg and Theodore K. Rabb. Princeton: Princeton University Press. 6, 7

Kelly, Morgan and Cormac Ó Gráda. 2010. Living Standards and Mortality since the Middle Ages. Working paper School of Economics, University College Dublin. 3, 7, 10

Koepke, Nikola and Joerg Baten. 2005. "The Biological Standard of Living in Europe during the Last Two Millennia." European Review of Economic History 9(01):61-95. 6

Komlos, John. 2003. "An Anthropometric History of Early Modern France.” European Review of Economic History 70:159-189. 7

Lamb, H. H. 1995. Climate, History and the Modern World. Second ed. London: Routledge. 6,19

Le Roy Ladurie, Emmanuel. 1971. Times of Feast, Times of Famine: A History of Climate since the Year 1000. New York: Doubleday. 7

Maddison, Angus. 2009. Statistics on World Population, GDP and Per Capita GDP, 1-2006 AD. WWW document URL: http://www.ggdc.net/maddison/. 20 
Mann, Michael E. 2002. Little Ice Age. In Encyclopedia of Global Environmental Change, ed. Michael C. McCracken and John S. Perry. Wiley. 2, 6

Mann, Michael E., Zhihua Zhang, Scott Rutherford, Raymond S. Bradley, Malcolm K. Hughes, Drew Shindell, Caspar Ammann, Greg Faluvegi and Fenbiao Ni. 2009. "Global Signatures and Dynamical Origins of the Little Ice Age and Medieval Climate Anomaly." Science 326:1256-1260. 2, 6

Matthews, John A. and Keith R. Briffa. 2005. "The 'Little Ice Age': Re-evaluation of an evolving concept." Geografiska Annaler 87 A:17-36. 2, 6, 14

McGovern, T. H. 1981. The Economics of Extinction in Norse Greenland. In Climate and History, ed. T. M. L. Wrigley, M. J. Ingram and G. Farmer. Cambridge: Cambridge University Press pp. 404-433. 19

Miskimin, Harry A. 1975. The Economy of Early Renaissance Europe, 13001460. Cambridge: Cambridge University Press. 20

Parker, Geoffrey. 2001. Europe in Crisis: 1598-1648. Oxford: Blackwell. 7

Pfister, C. 1992. Monthly Temperature and Precipitation in Central Europe 15251979. In Climate Since A.D. 1500, ed. R.S. Bradley and P.D Jones. London: Routledge. 20

Pinheiro, Jose C. and Douglas M. Bates. 2000. Mixed Effects Models in S and S-PLUS. New York: Springer. 8

Postan, M. M. 1975. Medieval Economy and Society. Harmondsworth: Penguin. 7

Sargent, Thomas J. 1979. Macroeconomics. New York: Academic Press. 5

Slutsky, Eugen E. 1937. "The Summation of Random Causes as the Source of Cyclic Processes." Econometrica 5:105-146. 5 
Steckel, Richard. 2004. "New Light on the "Dark Ages": The Remarkably Tall Stature of Northern European Men during the Medieval Era." Social Science History 28:211-229. 6, 7

Tainter, Jospeh A. 1988. The Collapse of Complex Societies. Cambridge: Cambridge University Press. 6

Teraesvirta, T, C. F. Lin and C. W. J. Granger. 1993. "Power of the Neural Network Linearity Test." Journal of Time Series Analysis 14:209-220. 15

van Engelen, A.F.V., J. Buisman and F. IJnsen. 2001. A Millennium of Weather, Winds and Water in the Low Countries. In History and Climate: Memories of the Future?, ed. P. D. Jones, A. E. J. Ogilvie, T. D. Davies and K. R. Briffa. Boston: Kluwer Academic. 20 